\title{
THE WEST SEPIK GNAU WERE NEVER IN GUAM AND OTHER FACTUAL ERRORS!
}

\author{
Gary M. Heathcote, Anthropology Resource \& Research Center, University of Guam \\ zinjman@uog.edu
}

In the literature on reference accuracy in science and medicine (e.g. see Poyer 1979; Siebers and Holt 2000; Ravendran 2003), attention is virtually restricted to bibliographic errors regarding names and initials of authors, title of article, journal title, year, volume, page numbers, and so on. It seems to me that such errors can be considered minor, or of a first degree, in relation to higher echelon desiderata that a published author should not only give other authors proper credit where credit is due, but accurately represent and at least competently -if not masterfully- discuss their work. To continue my simple classification, reference errors of a second degree can be said to occur when an author discusses another's (cited) work in a way that reveals that s/he has not entirely understood -at all levels of meaning and nuance- what the latter author intended to communicate. Finally, there are yet more serious errors, of a third degree, that fully and persistently misrepresent the work of others.

I am sorry to inform the editors of Chungara that some third degree reference errors have appeared in three articles published in the volume 32, number 2 issue on syphilis in the Americas (viz. Reinhard et al. 2000; Rothschild and Rothschild 2000; Saunders et al. 2000). These three articles contain misrepresentations of published and unpublished articles and reports.

The first misrepresentation concerns the antiquity and ethnohistorical documentation of yaws in Guam:

Yaws was the only treponemal disease present in Guam prior to 1668 (Heathcote 1991; Howells 1973; Rothschild and Rothschild 1995; Stewart and Spoehr 1952).

-- Reinhard et al. (2000, p. 3 of online version)

-- Rothschild and Rothschild (2000, p. 3 of online version)

Yaws was the only treponemal disease present in Guam prior to 1668, when it was reported in the logs of the first ships to make landfall
(Baker and Armelagos 1988; Heathcote 1991; Howells 1973; Stewart and Spoehr 1952).

-- Saunders et al. (2000, p. 5 of online version)

These nearly identical assertions literally or essentially repeat a passage from an earlier work by Bruce and Christine Rothschild:

(Yaws was the only treponemal disease present in Guam prior to 1668 [Heathcote 1991; Howells 1973; Rothschild and Rothschild 1995; Stewart and Spoehr 1952]).

-- Rothschild and Rothschild (1996:556)

While yaws, among the treponemal diseases, likely was present in Guam prior to European contact, in 1521 (the above mentioned 1668 date refers to the beginning of effective Spanish colonization), the "supporting" studies credited above are misrepresented or inappropriately cited. This misinformation perpetuates errors that several colleagues and I (Heathcote et al. 1998) attempted to correct seven years ago. In our critique of Rothschild and Rothschild (1996), we endeavored to correct referencing errors that they had committed:

Heathcote's (1991) report on the Gognga-Gun Beach human remains is, in fact, mute on the history of yaws in Guam... Likewise, a thorough search of Howells (1973) fails to reveal any mention of yaws whatsoever. And while Stewart and Spoehr (1952) presented a strong argument that prehistoric Mariana Islanders from a site on Tinian (not Guam) bore the skeletal manifestations of yaws, their article contains appropriate caveats regarding this diagnosis.

-- Heathcote et al. (1998:361)

Both Reinhard et al. (2000) and Rothschild and Rothschild (1996, 2000) cite an earlier Rothschild and Rothschild (1995) article in support of yaws 
being the one and only treponemal disease with a deep history in Guam. And what does the latter article offer in the way of such support? The "support" offered relates to Baker and Armelagos (1988) allegedly delving into Guam's ethnohistorical record:

... Yaws was the only treponemal disease present in Guam prior to 1668 [here they provide number citations for Baker and Armelagos 1988; Heathcote 1991; Howells 1973; and Stewart and Spoehr 1952]... Indeed, Baker and Armelagos cite Daupier(sic) in 1703 as further support of this fact, and subsequent medical records do confirm the presence of yaws before 1668.

-- Rothschild and Rothschild (1995:1403)

The above claim misrepresents Baker and Armelagos (1988), and a gloss of this mis-citation appears in the Saunders et al. (2000) Chungara paper. In fact, Baker and Armelagos said nothing about "Daupier's" (Dampier's) 1703 observations (allegedly pertaining to Guam); indeed they do not cite Dampier at all. Dampier (1703) was, however, cited by Drusini (1988) in a "Comment" on Baker and Armelagos (1988), but Guam is not mentioned. What she did say was this:

We must bear in mind that the European explorers of Southeast Asia and the Pacific Islands from the Renaissance to the modern age have found yaws among natives of humid and hot areas [see, for example, Dampier1703].

-- Drusini (1988:722)

While neither Baker and Armelagos (1988) nor Drusini (1988) mentioned William Dampier on Guam, this English mariner and privateer did indeed visit Guam on three occasions, between 1686 and 1710 (Rogers 1995). Following his first voyage (1686), Dampier described Guam natives as follows:

The Natives of this Island are strong-bodied, large-limb'd, and well-shap'd. They are Copper-coloured, like other Indians; their hair is black and long, they eyes meanly proportioned; they have pretty high Noses; their Lips are pretty full, and their Teeth indifferent white. They are long-visaged, and stern of countenance; yet we found them to be affable and courteous. There are many of them troubled with a kind of Leprosie. This distemper is very common at Mindanao......

-- Dampier in Lévesque (1996:544); emphasis mine

It is important to note that while Dampier's observation that "a kind of Leprosie" was apparently well-established in Guam by 1686 may well bear on the issue of treponemal disease (and not leprosy) in Guam, it offers no robust support to the repeated declaration of Rothschild and Rothschild (and, now, their colleagues) that yaws was the only treponemal disease in Guam prior to 1668 .

Returning to the Saunders et al. (2000) statement that ".... In Guam prior to $1668, \ldots$ it (yaws) was reported in the logs of the first ships to make landfall.", again their citations seemed suspect. As neither Heathcote (1991), Howells (1973) nor Stewart and Spoehr (1952) said this, Baker and Armelagos (1988) was scoured for such a statement. None was found. Indeed, Baker and Armelagos do not mention Guam anywhere in their article.

In an even more egregious misrepresentation, Saunders et al. (2000), draw on misinformation presented in Rothschild and Rothschild (1996), and conclude their paper with this paragraph:

As syphilis and Yaws appear mutually exclusive and as syphilis only replaced Yaws in Guam subsequent to elimination of Yaws (Lewis 1975), the suggestion is that some event in the 1590-1640 interval was responsible for the eradication of Yaws [in a region which is now upstate New York]. The obvious consideration is a direct or indirect effect of European contact.

-- Saunders et al. (2000, p. 6 of online version)

The basis for this conclusion is Saunders et al.'s (2000) contention that the observer Lewis (1975) was able to establish that syphilis replaced yaws in Guam only after the latter was eliminated. This assertion restates earlier discussions of the Rothschilds':

The observation that syphilis occurred in Guam only after yaws was eradicated (Lewis 1975:84) suggests that the pre-Columbian New World occurrence of syphilis may represent a 
similar replacement phenomenon. The suggestion is that the organism responsible for yaws mutated at one location in North America to produce a new disease and that new disease spread, replacing yaws.

-- Rothschild and Rothschild (1996:560)

The above statement is utter nonsense, as Lewis was writing about the Gnau people of the Sepik Hills of New Guinea! Previously addressing the Rothschilds' (mis)representations of Lewis (1975), my colleagues and I suppressed our incredulity in making these statements:

This claim [replacement of yaws with syphilis on Guam, only after eradication of the former] suggests unfamiliarity with the geography and ethnohistory of Oceania. The work by Lewis is about the Gnau people of the Sepik Hills of New Guinea, and there is no mention of Guam anywhere in the book. On p. 84, Lewis merely notes that he recorded no stigmata from congenital syphilis among the Gnau, possibly because previous yaws infection provided relative immunity.

-- Heathcote et al. (1998:361; emphasis added)

The Rothschilds' continued misrepresentations of Lewis (1975) are truly remarkable; especially so in the more recent Saunders et al. (2000) paper, published two years after being corrected in print (Heathcote et al. 1998). As the Heathcote et al. (1998) paper has been subsequently cited by the Rothschilds (Rothschild and Rothschild 1999; Rothschild 2000), the persistence of this factual error is beyond my ability to fathom.

I have two motivations for writing this letter. The first is to correct, yet again, factual errors in publications by the Rothschilds. Secondly, I wish to underscore the importance of professional ethics and standards in scientific publications. Persistent misrepresentation clearly violates the canons of scientific reporting.

\section{References Cited}

Baker, B.J., and G.J. Armelagos

1988 The origins and antiquity of syphilis. Current Anthropology 29:703-720, 729-737.

Dampier, W.

1703 A New Voyage Round the World. James Knapton, London.

Drusini, A.

1988 Comment on The origins and antiquity of syphilis by B.J. Baker and G.J. Armelagos. Current Anthropology 29:721-723.

Heathcote, G.

1991 Report on the Human Osteology of the Gognga-Gun Beach Locale: Phase I, Descriptive Work. Unpublished Ms. submitted to the University of Guam Research Council. On file at Anthropology Resource \& Research Center, University of Guam.

Heathcote, G.M., A.L.W. Stodder, H.R. Buckley, D.B. Hanson, M.T. Douglas, J.H. Underwood, T.F. Taisipic, and V.P. Diego 1998 On treponemal disease in the Western Pacific: corrections and critique. Current Anthropology 39:359-368.

Howells, W.W.

1973 The Pacific Islanders. Charles Scribner's Sons, New York.

Lévesque, R.

1996 History of Micronesia: A Collection of Source Documents. Volume 8: Last Chamorro Revolt. Lévesque Publications, Gatineau, Québec, Canada.

Lewis, G.

1975 Knowledge of Illness in a Sepik Society. London School of Economics Monograph 52.
Poyer, R.K.

1979 Inaccurate references in significant journals of science. Bulletin of the Medical Library Association 67:396-398.

Ravendran, R.

2003 Editorial: Accuracy of references: whose responsibility is it? Indian Journal of Pharmacology 35:280.

Reinhard, K., B. Rothschild, C. Rothschild, and L. Martin 2000 Recognition of treponematoses in post repatriation X Ray and CD ROM Nebraska record. Chungara 32:175178.

Rogers, R.F.

1995 Destiny's Landfall: A History of Guam. University of Hawai'i Press, Honolulu.

Rothschild, B.M.

2000 Preconceived notions and hypothesis testing: holes in the Blue Hole. Chungara 32:141-146.

Rothschild, B.M. and C. Rothschild

1995 Treponemal disease revisited: skeletal discriminators for yaws, bejel, and venereal syphilis. Clinical Infectious Diseases 20:1402-1408.

Rothschild, B.M. and C. Rothschild

1996 Treponemal disease in the New World. Current Anthropology 37:555-561.

Rothschild, B.M. and C. Rothschild 1999 On pseudoscience and treponemal disease in the Western Pacific. Current Anthropology 40:69-71.

Rothschild, C. and B.M. Rothschild

2000 Occurrence and transitions among the treponematoses in North America. Chungara 32:147-155. 
Saunders, L.P., B.M. Rothschild, and C. Rothschild 2000 Old World Origins of syphilis in New York. Chungara 32:179-184.

Siebers, R. and S. Holt

2000 Accuracy of references in five leading medical journals. Lancet 356:1445.
Stewart, T.D. and A. Spoehr

1952 Evidence on the paleopathology of Yaws. Bulletin of the History of Medicine 26:538-541. 